\title{
O AUDIOVISUAL COMO METODOLOGIA NO ENSINO DE FILOSOFIA PARA O ENSINO MÉDIO
}

\author{
Audiovisual as a methodology in Philosophy Teaching for High School \\ El audiovisual como metodología en la enseñanza de la Filosofía para la escuela \\ secundaria
}

\section{Paulo Sérgio Gomes Soares ${ }^{*}$, Cláudia Rezende Monteiro ${ }^{1}$, Elisangela Oliveira da Silva ${ }^{1}$. \\ ${ }^{1}$ Curso de Filosofia. Universidade Federal do Tocantins, Brasil}

*Correspondência: Coordenação de Filosofia. Av. NS15, Quadra 109N, UFT, Sala 16, CEP 77001-090. Palmas-

Tocantins.e-mailpsoares@uft.edu.br

\section{Artigo recebido em 15/04/2020 aprovado em 28/05/2020 publicado em 03/07/2020.}

\section{INTRODUÇÃO}

Atualmente, as tecnologias fazem parte das situações de sala de aula e precisam ser incluídas como ferramentas no processo de ensino e a aprendizagem, de modo que essa questão toca diretamente na formação de professores preparados para atuar em ambiente tecnológico e com estudantes que desejam uma didática e uma prática docente diferenciadas. Nesse sentido, entendemos que os professores necessitam de formação para atuar com metodologias alternativas e métodos que assimilem as diversas situações e contextos socioculturais. Com vistas nessas premissas, o projeto "O audiovisual como metodologia no Ensino de Filosofia" foi idealizado pela residente Elisangela Oliveira da Silva e desenvolvido no Colégio Estadual Girassol de Tempo Integral Rachel de Queiroz, com o apoio dos outros residentes.

O objetivo do projeto foi experimentar alternativas para ensinar a filosofar a partir do uso de ferramentas audiovisuais ou do uso delas para criar situações de aprendizagem, no caso, a produção audiovisual - a criação de sons e imagens sincronizados para obter como resultados videoclipes, lives e documentários, produzidos apenas com o uso do celular, uma tecnologia comum entre os estudantes do Ensino Médio.
A proposta permitiu que os estudantes se tornassem protagonistas de seu próprio aprendizado e pudessem manipular uma tecnologia do seu universo cotidiano, como o celular, para fins didáticos. Porém, em que medida o celular pode se tornar um aliado na prática educativa? Seria possível representar um tema filosófico em imagens audiovisuais com o apoio do celular? O artigo apresenta o resultado alcançado como resposta a essas questões.

\section{METODOLOGIAS E MATERIAIS}

O trabalho com a produção de vídeos foi desenvolvido a partir de uma oficina ofertada para cinco turmas da $3^{\text {a }}$ série do Ensino Médio, envolvendo um total de 174 estudantes, vários deles com algum nível de experiência com o uso de tecnologias, outros demonstrando níveis de criatividade e senso crítico em relação aos problemas sociais, ambientais, políticos, etc., que foram fundamentais para o sucesso do projeto. Na $3^{\mathrm{a}}$ série, no bimestre em que o projeto foi desenvolvido, o conteúdo curricular versava sobre "A existência ética", "A Filosofia Moral" e "Ética e Política" e a oficina de produção de vídeo foi realizada com o intuito de fazer com que os alunos criassem vídeos sobre os temas estudados - com um roteiro, num cenário específico, uso de figurino, elenco, 
direção, etc. - e com a gravação das cenas feitas com um celular.

O período de realização desse trabalho foi de aproximadamente um mês e meio. Os conteúdos estavam dispostos nos livros didáticos (COTRIM e FERNANDES, 2013), mas foi exigido aos estudantes que se fizessem pesquisas em outras fontes e escolhessem livremente uma temática para trabalhar, desde que respeitassem um ponto em comum: versar sobre o conteúdo curricular. Após a pesquisa, os temas escolhidos pelos estudantes foram os seguintes: violência contra a mulher, uso de drogas, convivência familiar, vivência na escola, preconceito, discriminação e corrupção. A tônica desses assuntos foi a vivência ética.

A oficina contou com a participação dos cineastas palmenses Nival Correia e Esdras Campos, que ensinaram técnicas de roteiro, atuação e fotografia, gravação de cenas com o celular e edição audiovisual. Ou seja, os estudantes tiveram acesso a métodos para aplicação e uso do roteiro e a criação de vídeos em sala de aula, que foram aprimorados durante o bimestre, tendo em vista que foram estimulados a experimentar, aplicando os saberes em atividades cotidianas e compartilhando as experiências em sala de aula como forma de treinar e assimilar o uso da tecnologia (celular) para o fim desejado, e com vistas na produção um trabalho para disciplina como forma de avaliação; uma forma inovadora de avaliar que estimulou a criatividade e a participação ativa dos estudantes divididos em grupos.

As filmagens foram feitas na escola, em ambiente preparado para implementar o roteiro, e também fora da escola e em horários diferentes das aulas. Entre os residentes, foi estimulado o uso da sala de aula invertida (BERGMANN; SAMS, 2016), uma metodologia ativa que exige o protagonismo dos estudantes na aprendizagem e na produção do conhecimento.
Com a sala de aula invertida, os estudantes foram levados a fazer pesquisas e coletar materiais em casa e participar de atividades laborais em sala de aula - em casa eles fizeram pesquisar e na sala de aula desenvolveram atividades interventivas e de produção de materiais didáticos, conforme o conteúdo curricular. A metodologia contou também com estímulo ao modelo freireano de educar, que valoriza o diálogo e a roda de conversa - como um círculo de cultura (FREIRE, 1987), permitindo o debate entre os estudantes do Ensino Médio.

\section{RESULTADOS E DISCUSSÃO}

$\mathrm{O}$ projeto surgiu com a possibilidade de usar o cinema como instrumento para o Ensino da Filosofia no Ensino Médio, como um desafio para tornar as aulas atrativas, mas sem perder a essência da Filosofia, bem como para responder a um problema apontado pela preceptora Claudia Rezende Monteiro, que salientou que os estudantes possuíam dificuldades na leitura, interpretação e produção de textos filosóficos.

Para colocar em prática o projeto, foi iniciado um trabalho de explanação da ideia de conceitoimagem concebido pelo filósofo argentino Julio Cabrera, considerando o planejamento do conteúdo programático a ser trabalhado nos 50 minutos para cada aula. Os residentes passaram por uma preparação - uma espécie de curadoria - para atuar nas aulas considerando o audiovisual como ferramenta de ensino e aprendizagem; foram orientados na montagem de posters, a fazer sinopses dos filmes e a trabalhar com os vídeos nas aulas de Filosofia, com foco nas imagens. Em relação a isso:

o filósofo argentino Julio Cabrera procurou uma alternativa: confrontar o cinema e a filosofia a partir de problemas, e mesmo de considerar a filosofia a partir de imagens, não simplesmente do texto escrito, que é a forma tradicional de exposição na filosofia. Para ele, a produção de conceitos não é um privilégio da atividade 
filosófica; o cinema também é capaz de criar conceitos - os conceitos-imagem, em contraposição aos conceitos-ideia da filosofia. É a partir do conceito-imagem que o cineasta pode convencer o espectador de alguma coisa, seja da alegria de viver ou da relação perversa entre o homem e a natureza (BARBOSA, 2011, s/p).

A ideia de conceito-imagem pode ser usada para sensibilizar e desenvolver a linguagem e a leitura cinematográfica, abrindo inúmeras possibilidades para o Ensino de Filosofia. Aos poucos as aulas de Filosofia se tornaram um espaço de debates sobre imagens e ideias sobre a criação de cenas, envolvendo os estudantes e a comunidade escolar. Os personagens dos vídeos foram os próprios estudantes, os professores, as merendeiras e a equipe de gestão da escola.

Os debates sobre cinema e a produção audiovisual - os vídeos - mobilizaram a escola. A comunidade escolar participou das atividades e todo o esforço rendeu bons frutos, pois, no segundo semestre de 2019, oito vídeos foram inscritos no IV Festival de Cinema Estudantil de Palmas - "Você na Tela", promovido pela Secretaria da Educação do Município de Palmas. A escola teve três vídeos premiados (1) e os estudantes foram recebidos na Secretaria Municipal de Educação (SEDUC) para participar da cerimônia de premiação.

\section{CONCLUSÃO}

O desenvolvimento desse projeto foi fundamental para a formação de professores, pois os residentes tiveram a oportunidade de trabalhar com uma metodologia alternativa para ensinar a filosofar, utilizando o celular como uma ferramenta no processo de ensino e aprendizagem, uma tecnologia demonizada e banida das salas de aula por ser considerada um instrumento de dispersão e, portanto, antipedagógico.

\section{AGRADECIMENTO}

Agradecemos à Preceptora, Professora. Cláudia Rezende Monteiro, e a toda a equipe gestora do CEGTI Rachel de Queiroz pela receptividade e apoio nas atividades e pela disposição em participar do programa, acreditando nessa parceria entre a escola e a universidade.

Todos os autores declararam não haver qualquer potencial conflito de interesses referente a este artigo.

\section{REFERÊNCIAS}

BARBOSA, L. Cabrera e o conceito-imagem: possibilidades de abordagem do audiovisual. Postado em 15/10/2011. Revista Universitária do Audiovisual. UFSCar. Disponível em: http://www.rua.ufscar.br/cabrera-e-o-conceitoimagem-possibilidades-de-abordagem-doaudiovisual/ acessado em 03/02/2020.

BERGMANN, J.; SAMS, A. Sala de aula invertida: uma metodologia ativa de aprendizagem. Trad. Afonso Celso da Cunha Serra. $1^{\text {a }}$ ed. Rio de Janeiro: LTC, 2016.

COTRIM, G.; FERNANDES, M. Fundamentos de Filosofia. 2. ed. São Paulo: Saraiva, 2013.

FREIRE, Paulo. Pedagogia do oprimido. $17^{\mathrm{a}}$ edição. Rio de Janeiro: Paz e terra, 1987.

\footnotetext{
1 Link da matéria na UFT sobre o festival e a premiação dos estudantes e divulgação na SEDUC: https://ww2.uft.edu.br/index.php/ultimas-noticias/26601-nucleo-de-filosofia-do-programa-de-residencia-pedagogica-sedestaca-em-trabalho-desenvolvido-em-escola-da-rede-estadual
} 